realistic thinking in regard to the secrecy problem in the Westem world, and put an end to some of the absurdities which have been hampering scientific discussion in the field of nuclear physics and which may well have contributed to misunderstandings or to swelling the suspicions which the U.S.S.R. seem only too ready to entertain.

\section{CHARGES MOVING IN AND NEAR THE SUN}

\section{Cosmical Electrodynamics}

By Prof. H. Alfvén. (International Series of Monographs on Physics.) Pp. viii +238 . (Oxford: Clarendon Press ; London : Oxford University Press, 1950.) 25s. net.

T $T$ has truly been said that this is the electro1 magnetic era in astrophysics. Earlier, electromagnetic theories of cosmic phenomena rested on a somewhat insecure foundation; now, however, observations of stellar and solar magnetic fields, of the motions of gas near sunspots, and of solar and galactic radio noise have made it clear that electromagnetic phenomena cannot be disregarded. A large part of F. Hoyle's book, "Some Recent Researches in Solar Physics" (see Nature, 165, 377; 1950), was concerned with such phenomena; and now we have a book by Prof. H. Alfvén on related topics.

The structure of Alfvén's book is essentially very simple. A short general survey is followed by three chapters discussing the motion of charged particles in a magnetic field, electric discharges, and the magneto-hydrodynamic waves which Alfvén himself first discovered. The ideas developed in these three chapters are then applied in a further three chapters to solar physics (sunspots, chromospheric and coronal temperatures, prominences, etc.), magnetic storms and auroræ, and cosmic radiation.

The book is theoretical and, save in the chapter on electric discharges, normally concerned with Alfvén's own researches. For example, in discussing the motion of charges in a magnetic field, a brief account only is given of Störmer's work ; most of the time is spent explaining a method originated by others, but which Alfvén has greatly developed. This method, which is applicable to particles of moderate energy, represents the motion as a spiralling about the lines of force, together with a drift across these. Alfvén does not concern himself with the details of the spiralling, but with the motion of a "guiding centre" about which the spiralling is supposed instantaneously to be taking place.

The valuable chapter on electric discharges is not the only feature which reminds one that the author is an electrical engineer. He likes to illustrate an argument by introducing the equivalent circuit. When, in the theory of magnetic storms, he finds it difficult to calculate the field of the current systems which he postulates, he uses a scale model to give him the results which he seeks. But his treatment of lines of force in the theory of magneto-hydrodynamic waves is the most typical. Many engineers speak as if they can see and count lines of force; and in Alfvén's theory the lines of force come to life, writhing and dragging a sticky material about with them.

Because of the clarity of the style, and the novelty of the ideas, the book is both entertaining and stimulating. That does not necessarily mean that the ideas are all correct; but they cannot fail to stimulate those who most disagree with them. Personally, I regard magneto-hydrodynamic waves as a valuable new concept; but I do not believe, as Alfvén does, that such waves are the cause of sunspots. Nevertheless, a doubter is hard put to it to explain the correlation which Alfvén finds between the spottedness in one hemisphere in a given sunspot cycle and that in the other hemisphere in the next cycle, a correlation which his theory easily explains. Equally one can have serious doubts about his theory of magnetic storms ; but if one rejects it, one must find an alternative explanation of the diurnal variation of the latitude of auroræ, of which he provides strong evidence.

However, two comments must be made. First, nearly all Alfvén's theories postulate a general mag. netic field of the sun. Observation has not finally decided whether such a field exists; but if it does, it is probably variable, and often far weaker (at the surface) than Alfvén supposes. Thus the numerical agreements with his theory which he often invokes are far less secure than he suggests. He argues ( $p$. 106) that the success of his theories of sunspots and magnetic storms is strong evidence of the existence of a field of the strength which Hale first found; but. an observing astronomer doubtful of the existence of such a field may be tempted to turn the argument round.

Again, Alfvén's theories have met criticisms from several quarters. He does not attempt to gloss over this fact; indeed, he sets out the objections to his discharge theory of solar prominences so forcefully that one almost wonders why he is not convinced by thern. Because of the criticisms, however, he has withdrawn from some of the positions confidently maintained in earlier papers, and the gaps thereby left have not been filled. Consequently his arguments too often are vague where they should most be clear. For example, it is noteworthy that in his theory of sunspots he now gives no complete explanation of the darkness of a spot, and his explanation of the generation of a magnetic field above the surface is only sketched and becomes progressively more difficult to grasp the more one tries to enter into details.

One may, perhaps, summarize one's impressions of the book in a sentence from the preface: "The scope of this book is more to put the problems than to solve them". Prof. Alfvén has put many problems, and those reading the book will be made furiously to think. But $I$ do not think that they will be satisfied to leave the solutions just as he has left them.

T. G. Cowling

\section{INTROGRESSIVE HYBRIDIZATION}

Introgressive Hybridization

By Edgar Anderson. (Wiley Biological Research Series.) Pp. ix + 109. (New York: John Wiley and Sons, Inc.; London: Chapman and Hall, Ltd., 1949.) 18s. net.

$\mathrm{T}$ this small book of a little more than a hundred. 1 pages, Prof. Edgar Anderson deals from a rather unusual angle with the quantitative and genetical aspects of the impact of one species upon another through the intermediary of a hybrid swarm. The quantitative methods which are described may find useful applications in population genetics, ecology, 